RELACult - Revista Latino-Americana de Estudos em Cultura e Sociedade e-ISSN 2016/Atual: 2525-7870 | e-ISSN 2015/2016: 2447-018X

\title{
Aproximaciones a la experiencia decolonial indígena en
}

\section{Hispanoamérica}

\author{
Aproximações à experiência descolonial indígena na América Hispânica. \\ Approaches to indigenous de-colonial experience in Hispanic America
}

Natalia Vanessa Ramírez Peña ${ }^{1}$

\begin{abstract}
Resumen
Este texto tiene como finalidad dilucidar un poco los principales conceptos del artículo: Desobediência epistêmica: a opção descolonial e o significado de identidade em política escrito por el pensador argentino Walter Mignolo, quien los desarrolla a partir de actividades decoloniales ejecutadas en varios terrenos geopolíticos de América Latina como Ecuador, Venezuela, Cuba y Bolivia, siendo este último uno de los ejemplos más desarrollado por el argentino gracias a su persistencia, impacto, duración y su deseo colectivo por liberarse de los efectos totalizantes propuestos por quienes han querido protagonizar la historia los últimos siglos. En vista de ello, serán tomados otros ejemplos similares que faciliten la apropiación de las temáticas, además de su discusión con aportes como los de Bhabha, Nolasco, Cusicanqui, ligados a su vez, a contribuciones incluidas en materiales audiovisuales extraídos de conferencias y comunicaciones orales, emitidas por los teóricos ya mencionados, así como por algunos indígenas de accionar decolonial.
\end{abstract}

Palabras-clave: Desobediencia epistémica; identidad en política; opción decolonial; pueblos indígenas

\section{Resumo}

Este texto destina-se a elucidar os principais conceitos do artigo: Desobediência epistêmica: A opção descolonial e o significado da identidade na política, escrito pelo pensador argentino Walter Mignolo, quem desenvolve o artigo a partir da análise de atividades descoloniais realizadas em diversas terras geopolíticas Da América Latina como o Equador, a Venezuela, Cuba e a Bolívia, sendo a última, um dos exemplos mais desenvolvidos pelo argentino devido à sua persistência, impacto, duração e desejo coletivo de libertar-se dos efeitos totalizante propostos pelos protagonistas da história nos últimos séculos. Em vista disso, serão incluídos outros exemplos semelhantes que facilitam a apropriação dos temas, além de sua discussão com contribuições, como as de Bhabha, Nolasco, Cusicanqui, ligadas, por sua vez, a contribuições incluídas em materiais audiovisuais extraídos de conferências e comunicações orais, emitidas pelos teóricos acima mencionados, bem como por alguns ativistas descolonais indígenas.

Palavras-chave: Desobediência epistêmica; identidade em política; opção descolonial, povos indígenas

\begin{abstract}
This text is intended to elucidate the main concepts of the article: "Epistemic disobedience: The decolonial option and the meaning of identity in politics", written by the Argentine thinker Walter Mignolo, who develops the article from the analysis of decolonial activities carried out in several Geopolitical lands of Latin America such as Ecuador, Venezuela, Cuba and Bolivia, the latter being one of the most developed examples by the Argentine because of its persistence, impact, duration and collective desire to free themselves from the totalizing effects proposed by the protagonists of history in the last centuries. In view of this, other similar examples will be included that facilitate the appropriation of the themes, besides their discussion with contributions, such as those of Bhabha,
\end{abstract}

\footnotetext{
${ }^{1}$ Mestrando do Programa de Pós-Graduação - Mestrado em Estudos de Linguagens (Universidade Federal de Mato Grosso do Sul, UFMS). Licenciada en lengua castellana (Universidad del Tolima, Colombia). E-mail: nataliavarape@gmail.com.
} 
Nolasco, Cusicanqui, in turn, linked to contributions included in audiovisual materials extracted from conferences and oral communications, issued by the aforementioned theorists, as well as by some indigenous decolonial activists.

Keywords: De-colonial option ; Epistemic disobedience; Identity in politics; Indigenous societies

\section{Introducción}

Dando finalización a las presentaciones individuales propuestas para la disciplina Literatura comparada: Fundamentos, orientada por el profesor Edgar Cézar Nolasco en la Universidade Federal de Mato Grosso do Sul, propongo en este documento una discusión que gire en torno a las relaciones existentes entre Desobediencia epistémica, Opción decolonial e Identidad en política, nociones abordadas en el texto Desobediência epistêmica: A opção descolonial e o significado de identidade em política del profesor argentino Walter Mignolo, a fin de reflexionar sobre el lugar del conocimiento en las sociedades que en el pasado fueron colonizadas, específicamente en América latina. Para ello, me valdré de lecturas realizadas a las propuestas de otros autores como Rigoberta Menchú, Edgar Cézar Nolasco, Homi Bhabha, algunos ejemplos sobresalientes de los más recientes proyectos decoloniales indígenas en Bolivia y Colombia, además de ciertos planteamientos comprendidos en el libro Histórias locais/ Projetos globais también de Walter Mignolo.

Lo anterior me induce a aclarar como primera medida, el espacio actual desde donde emito tal reflexión, pues revela mi posición epistemológica, lingüística y cultural. Así, digo que soy una mujer hispana, nacida en Chaparral (departamento del Tolima) una pequeña ciudad periférica del centro de Colombia, quien hoy en día vive en Campo Grande, Mato Grosso do Sul, Brasil, lugar fronterizo con Paraguay y Bolivia, al que llegué para realizar mis estudios de maestría hace un año y medio.

Estar situada en dicha ciudad ha permitido que perciba nuevamente la importancia de la cultura indígena (caso puntual, los Kaiowá y Guaraní, así como cierta presencia de ciudadanos bolivianos) dentro de nuestras comunidades latinoamericanas, pues entendí que la razão imperial moderna (MIGNOLO, 2003, p. 36) suele concebirla tan sólo como una minoría, independiente de su etnia, país al que pertenecen o de la legislación que a estos los cubra. Esto indica que aquí ha sido posible gestar un discurso decolonial (hoy en día visto como un motivo de investigación) teniendo en cuenta su epistemología de frontera, entendida como a saída para evitar tanto o fundamentalismo ocidental quanto não- occidental (MIGNOLO, 2008, p. 297), ya que su diversidad enriquece las historias locales que acompañan indirectamente la historia imperial. 

e-ISSN 2016/Atual: 2525-7870 | e-ISSN 2015/2016: 2447-018X

Menciono estas líneas porque en mi país así como en varios países andinos, determinados colectivos y personajes afrodescendientes e indígenas, como Evo Morales o Rigoberta Menchú, han logrado pensar proyectos decoloniales a partir del accionar político; eso no quiere decir que intentan adherirse a un partido político que esté dispuesto a acoger sus identidades multiculturales, sino que, sostienen la idea de concebir el estado como un lugar en donde no es posible la neutralidad y objetividad democrática defendida por la administración moderna, esto, a través de la identidad en política; acto decisivo para

A opção descolonial, uma vez que, sem a construção de teorias políticas e a organização de ações políticas fundamentadas em identidades que foram alocadas (por exemplo, não havia índios nos continentes americanos até a chegada dos espanhóis; e não havia negros até o começo do comércio massivo de escravos no Atlântico) por discursos imperiais (nas seis línguas da modernidade européia - inglês, francês e alemão após o Iluminismo; e italiano, espanhol e português durante o Renascimento), pode não ser possível desnaturalizar a construção racial e imperial da identidade no mundo moderno em uma economia capitalista. (MIGNOLO, 2008, p. 289)

O sea, los saberes occidentales (fundamentado en el conocimiento proveniente del latín, griego y luego en las principales lenguas europeas) han venido influyendo en los saberes específicos producidos en lugares más "Racializados" ${ }^{2}$ " de América Latina (nacidos del Quechua, Náhuatl, Guaraní, Aymara etc.), a tal punto de incentivar en los afectados, la necesidad de un pensamiento decolonial que sin deslegitimar ninguna de sus perspectivas, permitirá la consolidación de una epistemología alejada de verdades emanadas de la matriz colonial de poder, que logre la reivindicación de los derechos epistémicos bloqueados por las cosmologías occidentales y la casi tradicional prática de acumulação de conhecimento. (NOLASCO, 2013, p. 10)

En este orden de ideas, a continuación indagaré sobre determinadas manifestaciones de desobediencia epistémica, vigentes en América central y del sur cuyo enfoque no pretende ignorar el conocimiento institucionalizado por la razón colonial dominante, más si, resaltar en qué consisten las reflexiones intelectuales, o las opciones decoloniales, de los pueblos subalternos que luchan ahora por liberarse de la colonización epistémica, proveniente en gran parte de las naciones que contaban o cuentan aún con colonias territoriales y de las naciones que fueron colonizadas, pero que hoy hacen parte del proyecto de modernidad interesado en estandarizar la economía, y en efecto, el intelectualismo Claro está, a partir de los objetivos

\footnotetext{
${ }^{2}$ Ver: MIGNOLO, Desobediência epistêmica: a opção descolonial e o significado de identidade em política, p. 290
} 
políticos fijados por los gobiernos de dichos pueblos subalternos, puesto que estos reflejan el nivel de memoria histórica de sus promotores, su posición ante el neoliberalismo, así como la intención de rescatar la identidad perdida en gran parte tras la Ferida colonial (MIGNOLO, 2008, p. 304).

Dicha Ferida colonial, se inclina hacia el desacostumbrarnos a ver la realidad de una única manera, siguiendo la lógica del auto reconocimiento de las diversidades culturales, comprendidas tan pronto las sociedades moradoras de las fronteras creadas por la invasión europea, al mismo tiempo, generada de la experiencia de vivir en la exclusión, es decir, en la exterioridad. Los ejemplos traídos posteriormente, se enfocan en el actuar de un determinado grupo, los pueblos originarios, lo que no quiere decir que las reacciones decoloniales se producen en esos grupos, ya que podemos apuntar su aparición en otros ámbitos, como lo es el arte producido en América latina.

\section{La opción decolonial. Una alternativa para pensar las especificidades sociopolíticas de}

\section{América Latina.}

Si bien es cierto, la mayoría de historias locales de la parte sur del continente provienen en primera medida de las lecturas europeas, implementadas una vez que españoles y portugueses deciden alienar las comunidades ya consolidadas mediante la imposición de sus creencias, costumbres, idiomas, organización territorial; sin embargo, para comenzar a cambiar el orden de las cosas es ineludible comprender que todavía nos encontramos en la búsqueda de una emancipación que nos lleve a separarnos totalmente de aquellas imposiciones. Cuestión iniciada desde que se comenzaron a conformar las distintas naciones y que hoy en día procura manifestarse desde su exterioridad una vez revisadas las teorías itinerantes canónicas, cuyo local de nacimiento no es precisamente dicha exterioridad creada por la interioridad. Cuestión a la cual le podemos añadir el hecho de que no sólo las teorías se han movilizado, sino también muchos de los pensadores y artistas del continente, pues en tiempos de aceptación de la modernidad en América latina, fueron muchos los que viajaron a Europa, a fin de apreciar el desarrollo de las vanguardias artísticas para luego, por un lado intentar imitarlas, o por otro, brindarles una transculturación, como lo fue el movimiento antropofágico en Brasil nascido de la semana moderna en 1922.

Así, cuando digo exterioridad, hago referencia a la iniciativa moderna de crear conceptos como "Multiculturalismo" o "Subdesarrollo" para que aquellos que tienen poder económico y epistémico, continúen manejando su propia lógica centralizada, la misma que excluye todo rastro de cultura ajena a la occidental, (que pareciera como dice Achugar en su 
libro "Planetas sin boca" un pueblo sin historia), pero que homogeniza el mundo (al presentar modelos de educación, mercado...). Así pues, la cuestión decolonial implica repasar las teorías itinerantes, cuya esencia facilita problematizar la realidad pensar a partir da exterioridade e em uma posição epistêmica subalterna vis-à-vis à hegemonia epistêmica que cria, constrói, erege um exterior a fim de assegurar sua interioridade (MIGNOLO, 2008, p. 304).Es justamente la homogenización del interior (el sistema colonial moderno), lo que conlleva a analizar el exterior, ese pensamiento que aparentemente no concuerda con las categorías globales y no obstante, había logrado acatarlas a lo largo de los últimos dos siglos.

Según Achugar, talvez, a tarefa que temos daqui por diante seja a de construir com orgulho nosso raro balbucio, nossos raros balbuciantes escritos ou nossas balbuciantes falas, por sermos nós mesmos, e não que querem que sejamos.(ACHUGAR, 2006, p. 23)

Ahora bien, del mismo modo en el que Mignolo resalta en el gobierno del presidente Evo Morales la reciente organización política y económica boliviana, en donde se evidencia la Reciprocidad comunal ${ }^{3}$, caracterizada por la intención de desconectarse de los efectos totalizantes propuestos por quienes han protagonizado la historia, para reivindicar sus derechos indígenas, propongo otro ejemplo de gran similitud e impacto a nivel nacional en Colombia, el papel Consejo regional Indígena del Cauca (CRIC), del que mencionaré algunas de sus acciones decoloniales a continuación.

El CRIC, es el resguardo indígena (conformado casi por todos los indígenas del Cauca, adscritos a pueblos aborígenes como los Nasa, Guambianos, Guanacos entre otros) más consolidado hasta el momento en mi país, ubicado en el suroccidente de los Andes colombianos. Este consejo al igual que las demás organizaciones indígenas de Centro y Suramérica, especialmente las ubicadas cerca de la cordillera de los Andes, se vale de la autonomía dada por la constitución de 1991 para desarrollar su pluriversalidad en los territorios que les ha pertenecido a lo largo de su historia, es decir, defienden de las lenguas, costumbres y legislaciones que les competen una vez fue comprendida la intención extranjera de sobreponer identidades, traída hace más de 500 por los españoles. Desde este punto de vista, el consejo, en constante, diálogo con estado, mantiene una autoridad especial en lo respectivo a las regulaciones de su territorio, etnia y autoabastecimiento, pues aseguran que ninguna de las

\footnotetext{
${ }^{3}$ Ver: MIGNOLO, Desobediência epistêmica: a opção descolonial e o significado de identidade em política, p. 308
} 
leyes o normas implementadas en el mundo, se acogen a sus especificidades, pero para cambiar eso, es importante converger con la nación, solos no se puede. ${ }^{4}$

Los indígenas del Cauca son conscientes de su interculturalidad, por lo tanto, han sabido trabajar la tierra, convivir y educarse difumando la visión única de la realidad planteada por pensamiento occidental (ello no significa que ha sido desechado dentro de su toma de decisiones, dado el impacto que estas tienen), de ahí que

$\mathrm{Na}$ América do Sul, na América Central e no Caribe, o pensamento descolonial vive nas mentes e corpos de indígenas bem como nas de afrodescendentes. As memórias gravadas em seus corpos por gerações e a marginalização sócio-política a qual foram sujeitos por instituições imperiais diretas, bem como por instituições republicanas controladas pela população crioula dos descendentes europeus, alimentaram uma mudança na geo- e na política de Estado de conhecimento.(MIGNOLO, 2008, p. 291)

Entonces, los diversos grupos étnicos actúan en mayor o menor grado desde la decolonialidad, una vez que comprenden dos cosas: primero que su pasado fue marginado por los distintos modos de colonialidad, y segundo, la posibilidad de lograr políticas en las cuales se reconozca sus espacios, y disimilitudes culturales (sin que eso suponga retroceso o racismo), con relación a lo pregonado por los centros hegemónicos universales; cuestión que en América Latina está evolucionando debido a los estudios subalternos han permitido dilucidar como $A$ modernidade não pode ser entendida sem a colonialidade; a colonialidade não pode ser entendida sem a modernidade (MIGNOLO, 2003, p. 277), gracias a lo cual legislaciones y ámbitos académicos revelan la necesidad de trabajar desde el interior de su memoria. En otras palabras, no todos los patrones de vida, y en consecuencia, no todas las teorías imperantes podrían acoplarse naturalmente a cada una de las sociedades periféricas, nuestros países son testigo de eso, con base a esa idea, la crítica é eficente (BHABHA, 1998, p. 51), dado a que el crítico decolonial enuncia acatando los contenidos políticos de su lócus, provenientes en gran parte de discursos hegemónicos que comprometen sus perspectivas uma vez que o hibridismo cultural e histórico do mundo pós-colonial é tomado como lugar paradigmático de partida. (Ibid., p. 46). Eventualmente, podrá ser visto el aporte del crítico decolonial a partir de su posición como latinoamericano lo que permitiría establecer posibles diálogos con otras alternativas intelectuales, especialmente de tipo centralista cuya intención es la de pensar el

\footnotetext{
${ }^{4}$ Feliciano Valencia, representante del CRIC: Seminario en Derecho Propio e Intercultural y coordinación de Jurisdicciones. Disponible en https://www.youtube.com/watch?v=UGwgUqskMfw Acceso el 31 de octubre de 2016
} 
mundo siguiendo sus proyectos homogeneizadores, en efecto, habría reflexiones contemporáneas menos jerárquicas y mayor legitimación sobre todos los saberes que conforman, este, nuestro mundo, independiente del lugar de su emisión.

\section{La identidad en política como camino para quebrar los estados "Mono- Tópicos".5}

Entiendo que la invasión imperial/colonial europea, dada desde el siglo XV, propició a nivel político la configuración republicana del continente, lo que indica que la prevalencia de lugares con grandes similitudes y al mismo tiempo, con grandes diferencias, es algo latente desde la existencia de los imperios Maya, Azteca e Inca, en vista de que estos pueblos contaban con cosmologías y organizaciones sociales similares, concebían la naturaleza como lo más perfecto (de ahí que supieron manejar una agricultura sustentable), desarrollaron una arquitectura avanzada así como también dominaban distintas lenguas autóctonas e implementaban rituales acordes a sus cosmovisiones. Tal orden republicano hizo que muchas de las semejanzas que tenían las antiguas civilizaciones fueran conservadas por los pobladores mestizos y amerindios conscientes también de la presencia de tradiciones europeas y criollas, consolidando con el pasar de los años una hibridación cultural, ahora inmiscuida en cuestiones pos coloniales, inclinadas a universalizar las bases de la modernidad en todos los ámbitos.

Basándome en las históricas similitudes inherentes a los pueblos originarios que habitan las montañas mesoamericanas y los Andes, (de este último lugar tengo conocimiento, debido a que he tenido la fortuna de conocer y vivir cerca la región) es viable afirmar que tanto el discurso de los países andinos heredado de la colonia al igual que el pos colonial, es semejante, no solo por compartir la lengua que nos fue impuesta a fin de instituir un solo código comunicativo, sino también porque aún hace parte del proyecto colonial moderno. La identidad en política en sus diversos tipos de accionar, ha criticado el mencionado proyecto, es por eso que a pesar de haber vivido las pasadas y actuales intenciones hegemónicas, cada nación presenta distintos niveles de preocupación étnica, dependiendo sus fronteras gubernamentales y claro, diferentes modos de interculturalidad. Según lo asentado, la identidad en política es crucial, parafraseando a Mignolo, para que la opción decolonial una vez que sin teoría políticas establecidas y sin la organización de acciones políticas fundamentas en identidades, que fueron asignadas por los discursos imperiales, quizás pueda desnaturalizar la construcción racial e imperial de la identidad en el mundo moderno inmerso ya de por si, en una economía capitalista (MIGNOLO, 2008, p. 289).

\footnotetext{
${ }^{5}$ Ver: MIGNOLO, Desobediência epistêmica: a opção descolonial e o significado de identidade em política, p. 297
} 

e-ISSN 2016/Atual: 2525-7870 | e-ISSN 2015/2016: 2447-018X

De acuerdo con las palabras del profesor Mignolo, la identidad en política es pensar políticamente a través de acciones sujetas al escenario local, desde las que podamos ver el mundo y hablar por nosotros mismos (prácticas decoloniales), de tal manera que las sociedades no actuarían según la razón imperial de occidente, sino, siguiendo los principios específicos de su cultura y por ende de la razón subalterna que

Surge como resposta à necessidade de repensar e reconceitualizar as histórias narradas e a conceptualização apresentada para dividir o mundo entre regiões e povos cristãos e pagãos, civilizados e bárbaros, modernos e pré-modernos e desenvoltos e subdesenvolvidos, todos eles projetos globais mapeando a diferencia colonial. (MIGNOLO, 2003, p. 139)

En concordancia con lo expuesto, traigo a colación el caso de la líder indígena guatemalteca, Rigoberta Menchú, al confrontar aquellas divisiones expresadas por la "Política de identidad ${ }^{6 "}$ (sexo, raza, geografía, partido político) mediante la narración en un español aprendido a los 20 años, y con el cual, a propósito no se siente muy cómoda, de su propia historia personal y subalterna, relato en el cual su cultura quiché, su familia y ella, son los protagonistas. Menchú se vale del activismo social para luchar por los derechos de los pueblos amerindios de Guatemala y de todos aquellos que han recibido abusos, del hombre blanco influenciado por el colonialismo crítico interno que teima em imperar nas periferias (MIGNOLO, 2008, p. 289), es tan marcado compromiso con los campesinos e indígenas victimas del poder externo e interno que la hizo merecedora del premio nobel de paz en 1992.

De modo que su obra "Me llamo Rigoberta Menchú y así me nació la conciencia" surge de una entrevista concedida a la antropóloga venezolana Elizabeth Burgos. Allí narra los vejámenes que su familia y comunidad en general tuvieron que vivir a causa de los terratenientes y los gobiernos capitalistas (que aunque ya subalternos, generaron otro interior subalterno colonialista), dominantes en Guatemala, ella cuenta cómo ser indígena en una sociedad, donde el $90 \%$ de la población también lo es, puede ser sinónimo de ignorancia o de indio cuando los dirigentes apoyan la imposición de la modernidad/colonial.

Praticamente, os companheiros tem que aprender o castelhano como eu aprendi, tem que aprender a ler e escrever como eu aprendi e tem que ter toda a responsabilidade que eu tenho para o trabalho. Assim é que trocamos constantemente de tarefa, de trabalho. Por essa razão. Tivemos a experiência na Guatemala, pois sempre nos disseram: "Pobres índios, não podem falar." Então, muito dizem: "Eu falo por eles." Isso nos magoa muito. É parte da discriminação. E temos entendido que cada um é responsável pela luta, de não necessitamos de um dirigente que só elabora

\footnotetext{
${ }^{6}$ Ver MIGNOLO, Desobediência epistêmica: a opção descolonial e o significado de identidade em política, p. 289
} 

e-ISSN 2016/Atual: 2525-7870 | e-ISSN 2015/2016: 2447-018X

documentos, mas necessitamos de um dirigente que também, esteja em perigo, que também corra os mesmos riscos que todo o povo (MENCHÚ, 1993, p. 312).

Habría que decir también que la obra de la guatemalteca expone la manera en que los indígenas fundan jerarquías, ejecutan rituales, cuidan las tierras, respetan sus hábitos, este aspecto es uno de los más preservado ya que afirma:

\begin{abstract}
De acordo com nossa cultura, nossos antepassados se escandalizam muito de ver todas as coisas modernas. Por exemplo, o planejamento familiar, com o qual tapeiam o povo e lhe tiram dinheiro. Essa é uma parte da reserva que temos guardado para não permitir que acabem com nossos costumes, com nossa cultura. O indígena tem sido muito cuidadoso com muitos detalhes da própria comunidade e não é permitido, por parte da comunidade, falar sobre muitas coisas de detalhes do indígena. E eu mais ainda, porque chegaram teólogos que viram e que tiram outra concepção do mundo indígena. Então, para o indígena é muito doloroso que um ladino use roupa indígena. É um escândalo para o indígena. Tudo isso tem contribuído para que a gente guarde muitas coisas e que a comunidade não queira que se conte isso.(Ibíd,. 42)
\end{abstract}

Ambos fragmentos, que a propósito escribo en portugués porque mi primer contacto con el libro de la líder guatemalteca fue mediante la versión en lengua portuguesa, pues es más fácil adquirirlo así ya que es la lengua oficial del lócus en el cual habito y por ende, ha sido en esta lengua en donde lo he sabido comprender primeramente (no por sentirme discriminada, más si por la intención interpretarla bajo los conceptos de la cultura en donde estoy inserida, que hoy en día es mi hogar), si bien su publicación original sea en español, mi lengua nativa. Reflejan la discreta resistencia con que algunos de los pueblos indígenas han sobrevivido, cuestionando el progreso mundial, en aras de proteger las costumbres heredadas de su pasado, actualmente y desde hace siglos tan vulnerable al sometimiento, y juzgamiento ejercida por los poderosos.

Así mismo, la situación de Menchú la condujo a ser candidata presidencial en dos ocasiones, ya que reconoce la necesidad de contribuir a la crítica del sistema totalizante proponiendo formas subalternas de pensar (NOLASCO, 2013, p. 10.), y desde luego, ir desfazendo e ultrapassando a subalternidade inerente, (Ibid,. p. 10)sabe que la situación y la de los suyos tienen eco en los demás pueblos indígenas de América, por tanto, sigue, trabajando de modo similar al CRIC, siguiendo el pensar descolonialmente e agir politicamente de forma a não permanecer dentro da razão moderna como sua política imperial de identidades(Ibid,. p. 10).

\title{
3. Desobediencia epistémica. El primer paso para la formación de sociedades más justas.
}



e-ISSN 2016/Atual: 2525-7870 | e-ISSN 2015/2016: 2447-018X

Continuando con la tercera y última parte de este documento, intentaré referirme al punto central del texto de Mignolo, la asimilación y aplicación de saberes forasteros en un terreno siempre controlado por las teorías sociales, mercantiles y políticas, nuestra América. Cuando digo América estoy refiriéndome a los países que localizados entre México y la región de la Patagonia, en Argentina, en vista de que muchas veces pareciera que el término América le compete solo a la mayor parte de Norteamérica, clasificando a la otra sección del continente como "Países en vía de desarrollo", al encontrarse en un aparente estado de transición económico que implementa conceptos modernos e eurocentrados (MIGNOLO, 2008, p. 288), planteados por las potencias mundiales, con el propósito de guiar dicho desarrollo a las dinámicas socioeconómicas que estas promueven.

En este sentido, el profesor Mignolo no brinda conceptos de ninguna de las temáticas que abarca, debido a que sostiene que eso sería continuar en la retórica de la definición, como le sucedió en un encuentro en la Universidad Complutense de Madrid. Según él:

\footnotetext{
Um outro sociólogo da platéia perguntou, com a certeza que ser um sociólogo lhe dava, "Você podia definir pensamento descolonial? Você nos deu uma história, usouo metaforicamente, mas você nunca nos deu uma definição". Eles estavam pedindo obediência epistêmica. Não lhes ofereci, claro, uma definição porque isso teria significado jogar de acordo com as regras que ele estava me pedindo para jogar que era "identidade disciplinar". E ele se recusava a jogar com as regras que eu estava jogando, que era a racialização dos corpos e das localidades geo-históricas. Ou seja, eu não estava jogando o jogo da identidade disciplinar, mas o da "identificação geo-e do Estado" como foi formada e moldada, no mundo moderno/ colonial, pela retórica da modernidade justificando a economia capitalista (MIGNOLO, 2008, p. 288).
}

A fin de cuentas, lo que pretendía era considerar la opción decolonial, pues los sociólogos y marxistas (mayoritariamente europeos) del encuentro creían en una identidad que había nacido en sus localidades, sin pensar que Mignolo intentaba desprenderse del eurocentrismo para exponer sus particularidades identitarias.

Traigo este ejemplo del autor porque algo parecido les sucede a los indígenas que acatan como opción decolonial la posibilidad de excluir la superioridad entre culturas, actitud promotora de la identidad en política, necesaria para la conformación de reflexiones epistémicas congruentes con la diversidad latinoamericana. Entendiendo esto, los intelectuales de estas tierras han concebido que Se por um lado, não temos suma exterioridade nesse mundo capitalista da modernidade, por outro lado, é bom que se entenda que não se trata de um fora ontológico, mas sim, de um fora conceitual criado pela própria retorica da modernidade [...] (NOLASCO, 2015, p. 45) 

e-ISSN 2016/Atual: 2525-7870 | e-ISSN 2015/2016: 2447-018X

Principio respaldando especialmente por intelectuales amerindios (No queriendo decir que los demás no lo hagan), cansados de lidiar con erudiciones alejadas de sus historias locales, que a la larga lo único que permiten es ilustrar los pensamientos dominantes que rigen el mundo, y que no favorecen el autoconocimiento local. Aunque no pretenden desconocer lo proveniente del centro, la intención gira en torno a estudiar la contemporaneidad desde la exterioridad, asumiendo o risco de não levar na bagagem os postulados conceituais pensados dentro de um sistema colonial moderno preconceituoso, elitista e sumariamente excludente (Ibíd., p. 45). Es así como la aimara, boliviana, Silvia Rivera Cusicanqui propone estudios involucrados en el rescate de la oralidad andina, cuyas formas van desde los análisis a los dialectos indígenas pasando por el dominio del español colonial y pos colonial, hasta reflexiones acerca de las luchas de campesinos e indígenas, marcadas por una heterogeneidad a que se mantiene viva gracias a las memorias del pasado prehispánico.

Por medio del activismo político, Rivera Cusicanqui debate el papel de la diversidad étnica, debido a que no se trata de cuidarla como si fuera algo arqueológico, sino de ponerla en interacción con la modernidad para superar la imagen de seres atrasados que nos dejó la colonia por el hecho de tener concepciones diferentes de la existencia y del mundo. A razón esto, afirmó recientemente en las Jornadas de literatura latinoamericana (JALLA), la importancia de la literatura de tipo indianista, como la de los boliavianos Franz Tamayo, Fausto Reinaga y Adolfo Costra du Rels, al presentar las subjetividades que fueron colonizadas injusticia social, la explotación dada a las riquezas de las montañas, sátiras a los gringos que poseen una visión instrumentalista de los animales en cuanto el indígena busca una convivencia equilibrada y la naturaleza de las tierras bolivianas. También, enfatiza en la modernización que nos exige reprimir el indio que llevamos dentro. Resalto textualmente ahora, una de sus apreciaciones

\footnotetext{
"Quiero refrescar algunas ideas para proponer una crítica a ciertas corrientes modernas de la colonialidade que ignoran la larga genealogía que tiene la preocupación sobre el hecho colonial, en países como el nuestro. Se produce un fenómeno de extrativismo intelectual y conceptual que refuerza estas formas colonizadas del conocimiento que de alguna manera todavía campean en nuestras universidades. Para ello voy a referirme a algunas formas peculiares de estos autores de hacer crítica literaria y crítica política, y Social en sus respectivas épocas ${ }^{7}$."
}

\footnotetext{
7 Presentación de apertura, dirigida por Silvia Rivera Cusicanqui, en la Jornadas Andinas de literatura latinoamericana (JALLA) en agosto de 2016, en la ciudad de La Paz, Bolivia. Disponible en https://www.youtube.com/watch?v=NiK8ryxssxM\&feature=share Acceso el 31 de octubre de 2016
} 

e-ISSN 2016/Atual: 2525-7870 | e-ISSN 2015/2016: 2447-018X

Por último, acentúa en la responsabilidad exige el uso de la palabra, este puede ser distinto pero nuestra humanidad, nos hace iguales, pertenecemos a una sola especie, aunque no a una sola lengua en vista de que estas son un regalo que ayudan a ver el universo de varias maneras, además, la multiplicidad de paisajes rurales y urbanos no pueden ser nombrados en una sola lengua, pues ninguna persona podría conocerlos todos. Cusicanqui cierra la presentación pidiendo la inclusión de saberes indígenas en los currículos universitarios y la necesidad de leer en lenguas nativas (se referiré a las aborígenes y a las lenguas oficiales de cada país), puesto que el exceso de traducciones convertirán nuestras bibliotecas, en cementerios.

La posición de la pensadora refuerza la idea de Mignolo sobre $O$ Fato de que comunidades indígenas e nativas foram convertidas ao sistema capitalista não significa que todo indígena das Américas tenha sido convertido (MIGNOLO, 2008, p. 308), en efecto la existencia de aquellos indígenas esquivos al capitalismo (o sea, de accionar decolonial), ha asegurado que la epistemología latinoamericana no caiga del todo en los juegos teóricos eurocéntricos, neoliberales o marxistas, en ningún momento pensados a partir das línguas e das categorias de pensamento não incluídas nos fundamentos dos pensamentos ocidentais. Novamente, grego elatim e (por favor repitam comigo...!)(MIGNOLO, 2008, p. 305) sino más bien, que sea concebida como el espacio donde dichas teorías son aplicadas, experimentadas y requeridas.

Es entonces en los recintos educativos, los lugares en donde el proceso de occidentalización debe seguir siendo confrontado, la parte inicial se ha venido dando a través de pensamientos y actos decoloniales tal como se dijo en líneas anteriores, de ahí que sean los académicos junto con los pensadores, las personas encargadas de estudiar, argumentar, difundir o al menos reflexionar acerca de las divergencias que nos componen socialmente, y no tanto los ideales globales que quieren silenciarnos con el fin de que todos aprendamos lo mismo, en otra palabras, aprender a desaprender los pensamientos itinerantes que han logrado viajar para lograr aprender el conocimiento que se ha gestado aquí.

Mas agora, em um mundo onde os processos civilizadores movem-se em todas as direções possíveis, os Estudos Subalternos poderiam contribuir para descolonizar a pesquisa, refletindo criticamente sobre sua própria produção e reprodução do conhecimento e evitando a reinscrição das estratégias de subalternização. (MIGNOLO, 2003, p. 277)

Trabajando en estas cuestiones, podría decirse que habría contribuciones directas en la trasformación de las comunidades de este lado del mundo. La labor continuamente 

e-ISSN 2016/Atual: 2525-7870 | e-ISSN 2015/2016: 2447-018X

mancomunada, procedente del quehacer decolonial del indígena y la posibilidad de forjar críticas académicas que vayan de la mano con nuestros cambios locales abrirá los caminos a la transculturación de conceptos, o desobediencia epistémica.

\section{Consideraciones finales}

Lo dicho hasta este instante, es tan sólo una breve mirada de los tópicos abordados por Mignolo, pues ahonda en ejemplos concretos por medio de la meditación, ya que evita caer en el juego de la argumentación en el cual la repetición de teorías domina, estrategia también utilizada por los demás autores estudiados a lo largo de la disciplina. Siendo así, me dispongo a cerrar con los siguientes puntos, dejando abierta la posibilidad de continuar complementando este documento. En congruencia:

Opino que la instrumentalización asignada al conocimiento provocó en los estudiosos del siglo XX y en los vigentes, el desprendimiento indirecto de la esfera pos moderna, una vez que la modernidad fue entendida como una nueva colonización, quiero decir, Foucault, Derrida o Lacan pasaron a hacer parte de una filosofía genérica, emergida de la única conciencia que han tenido, y que literalmente todo el mundo debía conocer, en el momento en que Fanon, Guamán Poma de Ayala y muchos otros (en solitario o en colectividad) supieron ofrecer propuestas originales que no concordaban con aquellas de discernimiento global, porque desciende dela conciencia que les fue segregada.

Dichas propuestas son resultado de una labor decolonial encabezada por la razón subalterna de la que nos habla Nolasco en A razão pós- subalterna da crítica latina". In: Cadernos de estudos Culturais: Pós-colonialidade, la cual, permitiría instituir una epistemología emancipada de la epistemología moderna adjunta a los conceptos occidentales y a la práctica de acumulación del conocimiento; de algún modo, viva primeramente en la mente de los indígenas y afro descendientes presentes en la extensión de América Latina, pues por generaciones, parafraseando a Mignolo, la marginalización a la que estuvieron relegadas, fue efecto del poder de las instituciones imperantes bien como por instituciones controladas desde la población descendiente de europeos, que alimentó algunos cambios en la geopolítica y en la política del estado en que se encontraba el conocimiento.

Conviene subrayar la insistencia del profesor Mignolo en lo que respecta a la identidad en política, en vista de que nada de lo anterior podría darse sin el creciente aumento del fenómeno de la identidad en política; aspecto que indica la dificultad de los pueblos originarios de convertir sus ideas en ideas competitivas cuando lo que procuran es la autonomía en sus valores epistémicos, acto que nos afecta a todas y todos, ya que somos sujetos políticos con o 

e-ISSN 2016/Atual: 2525-7870 | e-ISSN 2015/2016: 2447-018X

sin conciencia de ello. Esas ideas pueden también ser deliberadas en las diferentes colectividades subalternas pertenecientes o no a algún partido político, en vista de que para encontrar estabilidad hay que entender que el poder es algo difícil de tomar, ya que este no pertenece a ningún estado más si a las que Mignolo llama, pessoas politicamente organizadas. $^{8}$

\section{Referencias}

ACHUGAR, H. Planetas sem boca: escritos efêmeros sobre arte, cultura e literatura. Trad. de Lisley Nascimento. Belo Horizonte: Editora UFMG, 2006.

BHABHA, H. K. O local da cultura. Trad. de Myriam Ávila, Eliana Lourenço de Lima Reis, Gláucia Renate Gonçalves. Belo Horizonte: Editora UFMG, 1998.

BURGOS, E. Meu nome é Rigoberta Menchú e assim nasceu minha consciência. Tradução de Lólio Lourenço de Oliveira. São Paulo: Paz e Terra, 1993.

MIGNOLO. W. Histórias Locais / Projetos Globais: colonialidade, saberes subalternos e pensamento liminar. Belo Horizonte: Editora UFMG, 2003.

MIGNOLO, W. Desobediência epistêmica: a opção descolonial e o significado de identidade em política: Cadernos de Letras da UFF. Dossiê Literatura, língua e identidade, Niterói, $\mathrm{n}^{\circ}$ 34, p. 287-324, 2008.

NOLASCO, E. C. “A razão pós- subalterna da crítica latina”. In: Cadernos de estudos Culturais: Pós-colonialidade, Campo Grande - MS, v. 5, n. 9, 22, jan./jun. 2013.

NOLASCO, E. C. os condenados da Fronteira. in: cadernos de estudos culturais: Povos indígenas. Campo Grande- MS, v. 7. N 13. Campo Grande: Editora UFMS, 2015. p. 39-54

Silvia Rivera Cusicanqui - JALLA 2016. Disponible en https://www.youtube.com/watch?v=NiK8ryxssxM\&feature=share Acceso el 31 de octubre de 2016

Seminario en Derecho Propio e Intercultural y coordinación de Jurisdicciones. Disponible en: https://www.youtube.com/watch?v=UGwgUqskMfw Acceso el 31 de octubre de 2016

\footnotetext{
${ }^{8}$ Aquí, Walter Mignolo se está refiriendo a los indígenas bolivianos y a su clamor por la constante movilización, en el texto "Desobediência epistêmica: a opção descolonial e o significado de identidade em política", p. 312
} 